\title{
Prevention of Postoperative Adhesions of Caesarean Section
}

\author{
SZNASREEN $^{\mathrm{a}}$, S SHAHREEN ${ }^{\mathrm{b}}, \mathrm{SHUQ}^{\mathrm{C}}, \mathrm{S} \mathrm{HUQ}^{\mathrm{d}}$
}

\begin{abstract}
Summary:
Adhesions means fibrous or scar tissue that results from the healing process. Up to $95 \%$ of patients who have surgery develop adhesions. Adhesions formation and its long term sequel is a well known complication of the surgery but unfortunately very little is investigated about the prevention. The long term morbidities such as chronic pelvic pain, secondary infertility, hospital readmission, bowel obstruction, difficult repeat $C / S$ with increased bleeding, longer operative time, injury to bowel ,bladder, ureters and placental accreta spectrum disorder from adhesions are the main concern. The cost for these adhesions is extreme burden for the developing countries.
\end{abstract}

Several preventive agents against postoperative adhesions have been investigated. The proper surgical technique remains the cornerstone for good outcomes and risks reduction. Careful tissue handling, keeping tissue moist, meticulous homeostasis, minimization of tissue ishcaemia and avoiding excessive tissue desiccation, the use of micro and a traumatic instruments are very important to prevent the adhesive disorders. Several chemical agents, mechanical

Introduction:

Caesarean section(c/s) have been performed for more than 1000 years, till now this is the most common obstetric operation done all over the world(1) More than $90 \%$ of the women who undergoes $1 \mathrm{C} / \mathrm{S}$ have a repeat procedure in subsequent pregnancies ${ }^{2}$. Adhesions formation and its long term sequel is a well known complication of this surgery but unfortunately very little is investigated about the prevention of these adhesions ${ }^{3}$.

a. Prof. Shaikh Zinnatara Nasreen, Professor \& Head Dept. Obst. \&Gynae. Z H Shikder Women's Medical College Hospital.

b. Dr. Safinaz Shahreen, SHO, Portsmouth Hospital, UK.

c. Dr. Saleheen Huq, Medical Officer, Mymensingh Medical College.

d. Dr. Sabereen Huq, Medical Officer, Mymensingh Medical College.

Address of Correspondence: Prof. Shaikh Zinnatara Nasreen, Prof and Head OBS/GYNE, ZH Sikder Womens Medical College \& Hospital, E-mail zinnatn@yahoo.com

Received: 16 June 2015 Accepted: 23 December 2016 barriers and hydrofloatation are being used which seems to be promising. But all of them have some limitations. All these Barriers are being used widely but need to be properly evaluated, before its routine use. FDA approved Barrier Seprafilm, Hydrofloation Adept are popular but also CoSeal, SurgiWrap and Plasmax( not FDA approved) are getting much popularity. Oxidized regenerated cellulose is promising but for $\mathrm{C} / \mathrm{S}$ is not properly evaluated. The chemical barriers like NSAID, Steroids, antifibrinolytic agents and anticoagulant are being used since ancient period but they are not proved to be superior to adhesive barriers.

In the current state of knowledge, none can replace the good surgical technique. Therefore along with the training of appropriate surgical technique, preclinical or clinical studies are still necessary to evaluate the effectiveness of the several proposed prevention strategies and more researches are time demanding to prevent postoperative adhesions.

Key words: Postoperative adhesion, Caesarean section.

(J Bangladesh Coll Phys Surg 2017; 35: 86-90)

Adhesions means fibrous or scar tissue that results from the healing process.This healing process occurs after injury or inflammation to the organs and tissue. If the initiating events is not too intense, the body has mechanism to heal without formation of intense adhesions. Up to $95 \%$ of patients who have surgery develop adhesions as body wants to limit the spread the infection and anastomosis of the tissue. Most adhesions are mild and do not cause serious problems. Normal peritoneal healing involves a combination of fibrosis, fibrinolysis, and mesothelial regeneration ${ }^{4}$. But intense adhesions formation following $\mathrm{C} / \mathrm{S}$ occurs when normal fibrinolysis process is suppressed and lead to a cascade resulting adhesion formation. The adhesions usually occurs between loops of bowel or with- bladder, vaginal wall, abdominal wall ,that cause much morbidities, and is compounded by multiple $\mathrm{C} / \mathrm{S}$.

The rate of $\mathrm{C} / \mathrm{S}$ is increased dramatically for last two decades. Though mortality from $\mathrm{C} / \mathrm{S}$ has decreased but the morbidities especially with repeat $\mathrm{C} / \mathrm{S}$ is rising and 
is very alarming. Short term complications of $\mathrm{C} / \mathrm{S}$ like $\mathrm{PPH}$, septicaemia, embolism, pain, blood transfusion and retention of urine all are addressed and steps of prevention are adopted in most of the cases.

The adhesions result delay and difficult in delivery of foetus, more time consuming and challenging and may increase the risks of bowel or bladder injury with excessive blood $\operatorname{loss}^{5}$. The costs for these adhesions is extreme burden for the developing countries.

The long term morbidities such as chronic pelvic pain, secondary infertility, hospital readmission, bowel obstruction, difficult repeat $\mathrm{C} / \mathrm{S}$ with increased bleeding, longer operative time, injury to bowel, bladder, ureters and placental accreta spectrum disorder are not being evaluated properly therefore now this is high time to think how can we prevent the post surgical adhesions otherwise we have to face more maternal near miss death and also increased perinatal mortality and morbidities.

\section{The Usual Sites of Adhesions Formation}

Not only women suffer from long term sequels of post operative adhesions, the studies showed IUGR (intrauterine growth restriction), small for date, stillbirth and iatrogenic prematurity are also associated more withrepeat $\mathrm{C} / \mathrm{S}$ partially due to the adhesions. The exact mechanism of foetal effects is not known probably adhesions make hostile environment for the growing foetus.

\section{Factors Causing Adhesions}

Pelvic and abdominal adhesions develops after $\mathrm{C} /$ $\mathrm{S}$,mainly due to trauma, infection, ishcaemia, hypoxia of tissue, tissue desiccation, excessive manipulations, dissection of previous adhesions, presence of intra peritoneal blood and chemical irritants ${ }^{6}$. So obstetrician need to be careful about all these issues during the surgical technique.

There are other risk factors like reactive foreign bodies such as powder of gloves, suture materials, lint, fibers from textiles or papers all these increase the chance of

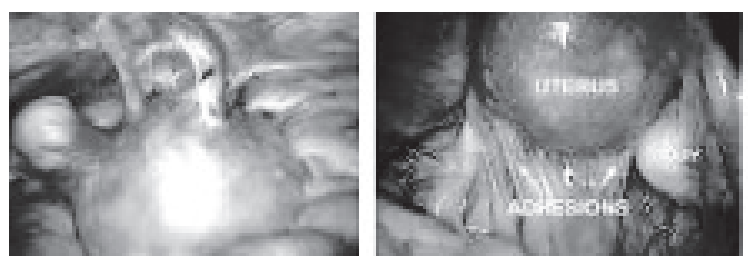

adhesions so not only surgeon but all the operative theatre staffs should be aware and need to be educated. Again patient factors can affect white blood cell and fibroblast activity such as nutritional status, anemia and some systemic disease and genetic variation are also responsible for adhesions formation. All patients who will go for surgeries or all the antenatal women need to be very well prepared physicallyahead of the surgery. Systemic diseases such as diabetes, hypertensions, asthma all must be controlled optimally.

Given the risk factors for adhesions formation, the surgical technique plays the most important role of prevention of adhesions. The rate of $\mathrm{c} / \mathrm{s}$ is increasing as epidemic. Numerous publications in last decade have demonstrated a consistently increase rate of adhesions ( $>90 \%$ in some cases) following $\mathrm{C} / \mathrm{S}$ and imposes huge costs for the society therefore any intervention that reduces the rate of $\mathrm{c} / \mathrm{s}$ and increase the rate of vaginal deliveries will reduce the maternal morbidities from adhesive diseases due to $\mathrm{C} / \mathrm{S}^{7}$.

The preventive strategies can be grouped into four categories

1. General principles.

2. Surgical techniques

3. Mechanical barriers

4. Chemical agents

General strategies for reduction of adhesions

Reducing rate of $\mathrm{C} / \mathrm{S}$ by increasing NVD, ECV, Partograph use and clear- cut protocols for $\mathrm{C} / \mathrm{S}$ complemented by good Governance with audit and accountability is the corner stone of prevention.

Adopting universal infection prevention procedures during surgery and prophylactic antibiotics,

Regular training and drilling foradhesions preventions program should be practicedamong the $\mathrm{O} / \mathrm{T}$ stuff and the surgical team.
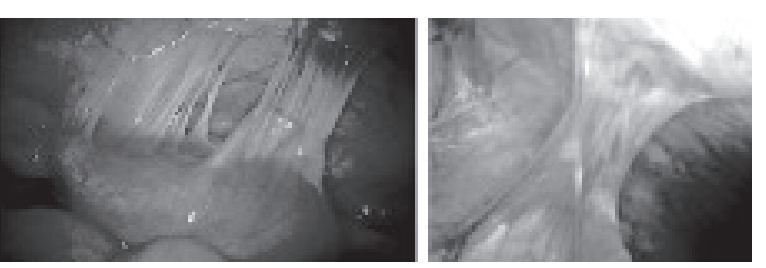

Fig.-1: Postoperative lesion adhesions of different sites in abdomen. 
Limited placements of intra-abdominal foreign bodies such as patches, much suture materials.

Use of moistened abdominal drapes and swabs and occasional application of saline solution to minimize dehydration of mesothelial surfaces.

Irrigation of the abdominal cavity to remove residual intra-abdominal blood depots prevent the adhesions.

\section{Surgical Principles to Prevent Adhesions}

The proper surgical technique remains the foundation for good outcomes and risks reduction. Careful tissue handling, keeping tissue moist, meticulous homeostasis, minimization of tissue ishcaemia and excessive tissue desiccation, the use of micro and a-traumatic instruments reduces serosal injury and these all have very importantrollto prevent the adhesive disorders ${ }^{8}$.

Avoidance of peritoneal contamination with infectious agents and foreign bodies is most crucial in prevention of adhesive disease. Irrigation of peritoneal cavity and packing the gutter to limit the spread of contaminants have no proven impact on adhesions, on the other hand the presence of foreign bodies and miscellaneous derbies, powdered glove is strongly associated with adhesions formationin fact US based movement aimed at banning cornstarch powder on surgical gloves ${ }^{9}$.

\section{Peritoneal Closure}

Huge debate is going on all around the world for the last two decades with numerous conflicting reports. During 1997 study showed that peritoneal closure is associated with increased adhesions formation $(28 \% \mathrm{v} /$ s $14 \%)^{10}$ also the Cochrane data base supported that study and study from the summary of 249 womenconcluded that closure of the peritoneum had advantages of reduced adhesions .

But this method was challenged by another metaanalysis by CHEONG and etal (in 2009) who showed that closure of peritoneum reduces adhesions formation significantly ${ }^{11}$.

Again another study by HAMEL and etal(in 2007) proved that closure of rectus and peritoneum resulted significantly fewer adhesions formations ${ }^{12}$. Similarly Myer and Bennett showed thatperitoneal non closure is associated with greater incidence of adhesions formation $^{13}$.

Very recently most powerful meta-analysis (2009_2011) was carried out by Z,SHI, etal. Their meta-analysis provided strong evidences that closure of peritoneum (both layers), during $\mathrm{C} / \mathrm{S}$, significantly reduces the risks of adhesions formation which will be beneficial to women undergoing repeated abdominal surgeries ${ }^{14}$.

Peritoneal closure is a safe surgical technique, which carries no significant short term hazards for the mother and there is no significant disadvantages over non closure of peritoneum.

\section{Incision Selection}

Pfannenstiel incision is the standard practice but too long incision causes par aesthesia and chronic pain. The JOEL-Cohen method (1995 ) was thought to be associated with reduction of time of delivery, bleeding and adhesions formation. The last findings was reviewed and a very recent data in (2010) found a link between single layer and increased incidence of bladder adhesions.

Longitudinal incision for both skin and uterus has its own risks.

However it is interesting to note that Cochrane data base concluded that "while $\mathrm{C} / \mathrm{S}$ is a common procedure performed on women worldwide, there is little information available regarding the appropriate incision.

\section{Mechanical Barriers}

Several preventive agents for postoperative adhesions have been investigated. Their roles are in activatingfibronolysis, hampering coagulation, diminishing the inflammatory response, inhibiting collagen synthesis, or creating a barrier between adjacent wound surfaces. Many products are available in the markets but not all of them fulfill the criteria's of ideal barriers.

\section{Properties for the ideal Adhesions Prevention Method}

Ideal Barrier should achieve the tissue separation and complete coverage ofadhesiogenic sites and it should remain there during the critical healing period. The adhesion barrier must not be permanent, should not require suturecan be used in presence of blood and it must not compromise thehealing.

But any product that is $100 \%$ effective at blocking fibrin deposition or suppressing immune function would prevent not only adhesions but also wound healing. So to choose the correct adhesive barrier is 
difficult.A Cochrane review published (in 2008) entitled Barriers- reduce the incidence of adhesions following surgery in pelvic and abdominal cavity. Following barriers meetmost of the criteria's. So these are FDA approved.

\section{The adhesive barriers areas following}

Sefra film the adhesion barrier used for abdominal and pelvic laparotomy.Interceed (TC7), CoSeal -mechanical adjunct in haemostasis, SurgiWrap and plasma concentrate the Pkasmax are also used.

The barrier consisting of oxidized regenerated cellulose (ORC) recently been introduced which is promising. 10 studies including 500 patients the meta-analysis demonstrated that it does $24 \%$ reduction in adhesions formation above the control group.

But the important prerequisite for using of this ORC needs meticulous haemostasis, which is not always possible in case of $\mathrm{C} / \mathrm{S}$.

Another very promising barrier the Sefrafilm approved by FDA for abdominal and pelvic laparotomy is extensively investigated. Cochrane Review of 2009 concluded that Sefrafilm reduces the incidence, extent and severity of adhesions. The Review recommended that Sefrafilm may be considered in the prophylaxis of intra-peritoneal adhesions.Seframil is recommended for laparotomy. ThoughSeframil is used in gynecological surgery and it significantly reduces the adhesions, for $\mathrm{C} / \mathrm{S}$ there is a clear need for a randomized, controlled trial to investigate its efficacy. Hiroshi Fushiki had randomized controlled trails on sefrafilm for 42 women who underwent $\mathrm{C} / \mathrm{S}$. He showed clearly that sefrafilm reduces the $\mathrm{C} / \mathrm{S}$ adhesions, easier delivery of babies, less time required and less bleeding during the repeat surgery $^{15}$.

\section{Seprafilm can be used in C/S specially in high risk group.}

It seem that none of the currently available methods for adhesion prevention can replace good surgical technique i,e meticulous hemostasis, gentle tissue handling, adequate irrigation, and careful use of energy sources. So adhesive disease can be partially preventable by improving the surgical technique and the use of barrier agents in selected cases.

Many newer drugs are coming up like recombinant adhesive barriertissue plasminogen activator an neurokinereceptor antagonist, methyl glutaryl coenzyme which might be an excellent choice for prevention of adhesions of $\mathrm{C} / \mathrm{S}$.

\section{Hydrofloatation}

Liquids are kept in the operate field so that it makes barrier between the organs during the healing process in an effort to float the intraabdominalstructures and prevent the contact. A host of substances includingCristalloid Ringer lactate, Dextran solution, 4\% icodexteine solution Liquid hyaluronic acid,inter gel, Auto-cross hyaluronic acid and Sepracoat have been utilized. FDA approved the 4\% icodextrin solution on the basis of head to head comparison with Ringer"sLactate ${ }^{16}$. Again their efficacy in $\mathrm{C} / \mathrm{S}$ is not proven to be significant.

\section{Adhesion Preventive Chemicals}

Since many years the chemicals are being used are-

NSAID Drugs, Steroids agents like corticosteroids along with anti-inflammatory plus antifibrinolytic agents, $\mathrm{Ca}$ channel blockers, anticoagulant Heparin and Fibrinolytic agents- Plasmin and Plasminogen activators. These chemical agents are not proved to be superior to adhesive barriers.

Postoperative adhesions are major health problems with a significant economic impact.Specially repeat $\mathrm{c} / \mathrm{s}$ are associated with placental disorder, peripartam hysterectomy, severe adhesive diseases leading increase incidence of readmission, bowel,bladder , and ureteric injury, intestinal obstruction,post operative drop of $\mathrm{HB} \%$, chronic pelvic pain and secondary infertility. We need to do researches to evaluate the effectiveness of the proposed preventive strategies with our limited resources in our perspective.

Finally to prevent the adhesive diseases - vaginal birth (VB) need to be encouraged, ECV, trial of VB after C/S, the use of partograph need to be ensured and counseling regarding risks of adhesions while discussing the mode of delivery, is important.

\section{Conclusion:}

$\mathrm{C} / \mathrm{S}$ is the most common surgical procedure in our country but we need to shift to more on $\mathrm{VB}$ (vagina birth). All the surgical team,theater staff should have the goal to minimize the risks of adhesions during $\mathrm{C} / \mathrm{S}$. It seems that none of the currently available methods for adhesion prevention can replace good "surgical 
technique". Therefore meticulous hemostasis, gentle tissue handling, adequate irrigation,universal aseptic precaution and careful use of energy sources need to be ensured. Maternal morbidities associated with adhesive disease can be prevented by improving the surgical technique and the use of barrier agents in selected cases. More research are needed for this important issue.

Further research into the mechanism underlying the formation of adhesions may allow the development of new methods of prevention, or a means of predicting which patients will develop adhesions, greatly enhancing their care.

\section{References:}

1 Boley, J.P. The history of caesarean section. Can Med Assoc J. 1991;145:319-322.

2 Martin, JA, Hamilton, BE, Ventura SJ et al.Birth; final dataor 2009.Natle Vital Start Rep.

3. Cunningham F, K. Leveno, S. Bloom, J.edsHauth (Eds.) Williams obstetrics. 23rd ed. McGraw Hill, Stamford, CT; 2010 .

4. Diamond MP, EL-Mowafi DM. Pelvicadhesions. SurgTechnolInt 1998; 7;273-83.

5. Rossouw JN, Hall D, Hardey J. Time between skin incision and delivery during Cesarean.Int J GynaecolObsstet $2013 ; 121 ; 82-5$.

6 González-Quintero, V., Cruz-Pachano, F. Preventing adhesions in obstetric and gynecologic surgical procedures. Rev Obstet Gynecol. 2009;2:38-45.

7 American College of Obstetric and Gynaecology; Society for Maternal Fetal Medicine.Obstetric care consensus no
1 safe prevention of the primary cesarean delivery. ObstetGynecol 2014;123;693-711.

8 Davey, A., Maher, P. Surgical adhesions: a timely update, a great challenge for the future. J Minim Invasive Gynecol. $2007 ;: 15-23$.

9. Edlich RF, Long WB $3^{\text {rd }}$,Gublar DK, et al.Danger of cornstarch powder on medical gloves; Seeking a solution. Ann PlastSurg 2009;63;111-5. in postoperative adhesions. Ann Surg. 1996;223:242-248.

10. McNally, O., Curtain, A. Does closure of the peritoneum during caesarean sectioninfluence postoperative morbidity and subsequent bladder adhesionformation? ObstetGynaecol. 1997;17:239-241.

11. Cheong, Y., Premkumar, G., Metwally, M., Peacock, J.L., $\mathrm{Li}$, T.C. To close or not to close?(A systematic review and a meta-analysis of peritoneal non-closure and adhesion formation after caesarean section). Eur $\mathrm{J}$ ObstetGynecolReprod Biol. 2009;147:3-8.

12. Hamel, K.J. Incidence of adhesions at repeat cesarean delivery. Am J Obstet Gynecol. 2007;196:e31-e32.

13. Myers, S.A., Bennett, T.L. Incidence of significant adhesions at repeat cesarean section and the relationship to method of prior peritoneal closure. J Reprod Med. 2005;50:659-662.

14. Z Shi, L Ma Y Yang, H Wang, A Schreiber, X Li e al. Adhesion formation after previouscaesarean section _a metalysis and systematic review. BJOG, Volume 118;no 4; march 2011;410-422.

15. Hiroshi Fushiki, Tomomi Ikoma, HirotoKobyashi, Hideo Yoshimoto.Efficacy of Sefrafilm as an Adhesion Preventive Barrier in Cesarean sections.Obstetric and Gynecol volume 91 no 5 2005/11 (557 561).

16. Brown CB, Luciano AA, Martin D, et al. Adept (4\% icodextrin) reduces adhesions after laparoscopic surgery for adhesiolysis. A double blind, randomized, controlled study.FertilSteril 2005;88;1413-25. 